\title{
EDUCAÇÃO AMBIENTAL POR MEIO DE DIAGNÓSTICO E MONITORAMENTO DA LAGOA DAS CAPIVARAS, EM GAROPABA (SC)
}

Cristina Machado Oliveira Faraco ${ }^{1}$

Resumo: Este artigo relata experiências de Educação Ambiental na Lagoa das Capivaras realizadas entre 2003 e 2013, na Escola de Educação Básica Professor José Rodrigues Lopes, em Garopaba, SC. Envolvendo turmas de Ensino Fundamental e Médio, foram realizados o diagnóstico ambiental e o monitoramento das qualidades químicas e físicas da água. Os resultados incluem a identificação de 25 espécies botânicas, 29 pássaros, 3 peixes e 3 répteis. As análises da água indicaram predomínio de taxas normais de $\mathrm{pH}$, ferro, ortofosfato e oxigênio, mas também valores altos de amônia e cloretos. Os alunos participantes apresentaram os resultados e trocaram experiências com a comunidade em eventos ligados à educação.

Palavras-chave: Educação Ambiental; Diagnóstico; Monitoramento; Sustentabilidade Socioambiental.

\footnotetext{
${ }^{1}$ Mestranda em Educação pela Universidade do Sul de Santa Catarina (UNISUL), Especialista em Gestão Ambiental pelo Instituto Superior de Educação e Pós-graduação (ISEPG)/Associação Catarinense de Ensino (ACE), graduada em Ciências Biológicas pela Universidade do Vale do Rio dos Sinos (UNISINOS) e professora titular de Biologia na rede estadual de Santa Catarina, na Escola de Educação Básica Professor José Rodrigues Lopes, em Garopaba.
} 


\section{Introdução}

A Lagoa das Capivaras, localizada no centro do município de Garopaba, em Santa Catarina, é um ecossistema que apresenta papel fundamental no suporte hídrico regional. Em vias de degradação, é um ambiente de importância socioambiental e espaço de grande potencial para o desenvolvimento de ações educativas sobre sustentabilidade, uma vez que se encontra dentro da zona urbana, no centro da cidade e próxima da maior escola estadual de Garopaba.

A Escola de Educação Básica Professor José Rodrigues Lopes, a maior Unidade Escolar da região (com cerca de 1.400 alunos nos três turnos letivos), situa-se nas redondezas, sendo que seus estudantes têm fácil acesso ao ecossistema. Diálogos abertos em sala de aula indicaram que a maior parte deles desconhece a lagoa, ou se já a visitaram, não têm consciência da sua importância para a qualidade de vida das pessoas e da urgência de sua conservação. Pensando neste quadro, no intuito de aproximá-los criticamente das questões socioambientais da comunidade, foram realizadas várias ações em Educação Ambiental (EA) por meio da pesquisa de campo. Através de diagnóstico ambiental, foram realizadas observações para o levantamento de espécies e de problemas socioambientais. Também, em parceria com pesquisadores da Universidade do Extremo Sul Catarinense (UNESC), foi realizado o monitoramento das qualidades químicas e físicas da água. Estas ações foram realizadas pelos próprios alunos sob a orientação da pesquisadora (como professora de Ciências e Biologia) e foram apresentadas e discutidas com a comunidade em eventos locais e regionais ligados à educação

Com base em estudos bibliográficos e nos dados levantados em campo, este artigo tem o objetivo de fazer um relato de experiências sobre os dez anos de ações em EA realizadas na Lagoa das Capivaras (entre os anos 2003 e 2013) com os estudantes da escola pública estadual do centro de Garopaba. Também, apresentar e discutir os resultados obtidos nas pesquisas de campo, como levantamento botânico, zoológico e de problemas socioambientais efetuados no diagnóstico, além das análises químicas e físicas da água, emitindo um parecer sobre a sua qualidade. Ainda, oferecer as sugestões propostas pelos alunos aos problemas levantados durante 0 processo educativo.

\section{Caracterização da Lagoa das Capivaras}

A Lagoa das Capivaras é considerada Área de Preservação Permanente pela Lei Federal no $4.771^{2}$ e está integrada à Área da Proteção Ambiental da Baleia Franca pelo Decreto Federal de 14 de setembro de 2000

2 Art. $2^{\circ}$, item b (BRASIL, 2002, p. 416). 
(BRASIL, 2012). Estas condições tornam tanto o corpo d'água quanto o seu entorno focos de conservação contínuos, uma vez que protegidos pela legislação brasileira.

Além de sua importância legal, exerce papel fundamental para o ecossistema regional por contribuir para a reposição dos recursos hídricos alimentando o lençol freático através do escoamento das águas das chuvas. Sua dinâmica e influência transcendem a comunidade e o município onde está localizada, pois é integrante do complexo lagunar sul-catarinense, formado pelas lagoas de Garopaba, Ibiraquera e Imaruí. Este é o início do maior complexo lagunar do mundo, situado no sul da América Latina e estende-se desde Garopaba até o Uruguai, na lagoa Mirim (MORELLI, 2001).

Sua conservação é fundamental para a garantia da qualidade de vida das atuais e futuras gerações, pois está interconectada com o maior reservatório de água doce potável do mundo: o Aquífero Guarani ${ }^{3}$. Este apresenta uma recarga anual (proveniente, principalmente, das chuvas) de 160 $\mathrm{km}^{3}$, sendo que, destes, $40 \mathrm{~km}^{3}$ constituem o potencial de exploração sem oferecer riscos ao sistema aquífero, conforme dados do relatório da Comissão Especial das Águas, desenvolvido pela Assembleia Legislativa do Rio Grande do Sul (2004).

Trabalhos científicos realizados nas últimas décadas ${ }^{4}$ mostram uma degradação gradual deste ecossistema devido ao aterro das margens, invasão imobiliária, deposição de lixo urbano e, principalmente, aos processos de eutrofização decorrentes do despejo de esgoto doméstico sem tratamento. $O$ assoreamento da lagoa em função dos processos erosivos decorrentes da derrubada da mata ciliar também é bastante evidente. Muitas construções foram erguidas em seu entorno, consolidando aterros que reduziram a sua área original a cerca de um terço. Esta ocupação desordenada traz como consequência de impacto ambiental a redução da zona de amortecimento dos impactos urbanos. Outro importante problema, relatado pelos pescadores locais, é o fato de que a lagoa costumava ser uma reserva de pesca nos tempos em que o mar não oferecia condições para tal atividade. Pela redução considerável de sua área, das suas espécies e números de peixes, além de seu estado de poluição, este tipo de atividade econômica de subsistência não pode mais ser realizado.

Há cerca de duas décadas, por iniciativa da Organização Não Governamental (ONG) Amigos do Meio Ambiente (AMA) e alguns moradores locais, teve início uma série de mutirões de limpeza da lagoa. Escolas públicas e também privadas desenvolveram atividades de EA com os seus alunos neste

\footnotetext{
${ }^{3}$ Abrange uma área subterrânea de água reservada em arenito de mais de 1 milhão e 200 mil quilômetros quadrados que se estende pelo Brasil, Argentina, Uruguai e Paraguai (MORELLI, 2001).

${ }^{4}$ Oliveira (2004), Mariano e Menezes (2010) e Costa e Menezes (2012).
} 
ecossistema. Alunos de Graduação, Especialização e Mestrado da Universidade Federal de Santa Catarina (UFSC), Universidade do Extremo Sul Catarinense (UNESC) e outras instituições trabalharam projetos de pesquisa envolvendo a EA, diagnósticos e técnicas de monitoramento da qualidade da água. Estas atitudes demonstram existir uma preocupação social com este ecossistema, tendo em vista o seu reflexo na qualidade de vida da comunidade e seu potencial de influência ecológica que transcende o município onde se encontra.

\section{EA por meio de diagnóstico e monitoramento}

A EA, enquanto processo que propõe desenvolver ações educativas para construção de conhecimentos, habilidades, valores sociais, atitudes e competências voltadas à conservação do meio ambiente por meio da reflexão crítica e a busca de soluções sustentáveis aos problemas socioambientais, ${ }^{5}$ apresenta diversas abordagens possíveis de práxis pedagógicas. De acordo com Layrargues (2004), o Brasil tem sido protagonista do debate sobre a resignificação dos sentidos identitários das diferentes posturas políticas e pedagógicas da EA, apresentando grande fertilidade de ideias a respeito. Apesar da heterogeneidade de nomenclaturas, a essência educativa mantémse voltada para ações reflexivas no âmbito da sustentabilidade ${ }^{6}$ social e ambiental, com riqueza de abordagens possíveis de serem trabalhadas tanto na educação formal quanto informal. Esta riqueza de abordagens não são formas solitárias e engessadas, mas podem dialogar, agregando um campo maior de ação e compreensão sobre a temática ambiental. É neste sentido que se construiu a base teórica e práxica deste trabalho.

A ação do educador ambiental não pode restringir-se apenas à transmissão tradicional de conceitos e conteúdos sobre o meio ambiente e a ecologia. Para Carvalho (2005), o educador deve ser um sujeito ecológico, que interage em permanente troca reflexiva no contexto dos processos sociohistóricos. Considera que a Natureza não é estática e, assim como o sujeito, está em constante movimento e reconstrução. Neste cenário, age de forma crítica e efetiva sobre a realidade socioambiental, no intuito de transformar a realidade-problema que se apresenta por meio de soluções sustentáveis, buscando agir de forma integrada, interagindo com os diferentes atores sociais envolvidos na problemática em estudo. Nesta perspectiva, como o ambiente é construção da interação entre a sociedade e a Natureza, cabe à sociedade, em sua relação com a Natureza, buscar intervir de modo prático, reflexivo e crítico na construção de uma realidade socialmente justa e ambientalmente

\footnotetext{
${ }^{5}$ Artigo $1^{\circ}$ da Lei $n^{\circ}$ 9.795, de abril de 1999 (BRASIL, 2002).

6 A sustentabilidade socioambiental propõe uma realidade onde o modo de vida individual e social, a política, a economia, as estruturas físicas e tecnológicas "não comprometam a capacidade intrínseca da Natureza de sustentar a vida" (CAPRA, 2003, p.238).
} 
sustentável. Pois ensinar, na concepção de Freire (2000, p.110), "[...] exige compreender que a educação é uma forma de intervenção no mundo". Uma forma de aprender a ter consciência crítica e reflexiva sobre a realidade para poder transformá-la, para melhorar a condição humana e do ambiente onde a humanidade se insere e interage". Para Dias (2000, p. 255), a EA apresenta-se como agente amplificador de uma educação cidadã em busca de mudanças para a melhoria das condições socioambientais:

A EA, por ser interdisciplinar; por lidar com a realidade; por adotar uma abordagem que considera todos os aspectos que compõem a questão ambiental - socioculturais, políticos, científico-tecnológicos, éticos, ecológicos, etc; [...] por ser catalizadora de uma educação para a cidadania consciente, pode e deve ser o agente otimizador de novos processos educativos que conduzam as pessoas por caminhos onde se vislumbre a possibilidade de mudança e melhoria do seu ambiente total e da qualidade da sua experiência humana.

De acordo com Braga e Marcomin (2012), práticas reflexivas em EA que envolvem o diagnóstico podem constituir ações efetivas para a sensibilização e a mudança de comportamento das pessoas. Oferecer condições para que as pessoas vivenciem atividades de pesquisa e investigação sobre a temática ambiental próxima de sua realidade favorece a formação de memórias, sentimentos e valores, sendo potencial instrumento para a sensibilização e para a construção de novas condutas mais alinhadas com a proposta da sustentabilidade socioambiental. Também, que as ações devem ser contínuas no contexto da comunidade para que sejam mais efetivas, reforçando estes valores e condutas e constituindo vivência transformadora em longo prazo.

Considerando as ideias dos autores citados neste capítulo, as ações de EA deste trabalho inseriram os alunos em um contexto real da sua comunidade, fazendo-os investigar e refletir criticamente acerca dos problemas próximos de sua vivência. No intuito de oferecer condições para o protagonismo de forma reflexiva e crítica na compreensão do mundo ao seu redor, as experiências propostas os desafiaram na busca de soluções sustentáveis aos problemas identificados. Nesta abordagem, os alunos tiveram os conteúdos científicos de modo a servir como base para pensar racionalmente as experiências empíricas vivenciadas em campo e na comunidade.

\section{Metodologia aplicada nas ações}

Este trabalho constituiu-se numa pesquisa de campo, de enfoque qualiquantitativo, valendo-se do estudo de caso da Lagoa das Capivaras como método de investigação. A metodologia da pesquisa de campo, segundo Pitsch et al. (1998), favorece a busca de respostas e soluções com base em 
observações de dados, fatos ou fenômenos, fazendo uma interpretação e leitura da realidade. Já o estudo de caso, contribui para a elaboração de um forte potencial de argumentação com os alunos, uma vez que consiste numa observação minuciosa e objetiva de uma situação real que necessita ser investigada e é desafiadora para os envolvidos (ANASTASIOU; ALVES, 2003).

As ações de EA realizadas na Lagoa das Capivaras envolveram duas centenas de alunos do Ensino Fundamental e Médio da Escola de Educação Básica Professor José Rodrigues Lopes, em Garopaba, SC. As ações ocorreram no período de 10 anos, entre 2003 e 2013, durante as aulas de Biologia, Ciências e em atividades extraclasse no contraturno.

Antes de levar os estudantes a campo, foram ministrados os conteúdos científicos pertinentes ao currículo proposto pela escola, que serviram de base teórica para o trabalho de campo. Após, foram construídos diálogos por meio de palestras expositivas sobre os princípios ecológicos (CAPRA, 2003) e a importância socioambiental da Lagoa das Capivaras para a comunidade. Nestes diálogos, os alunos foram motivados a buscarem, por meio de relatos seus e de familiares, sobre suas vivências, percepções e memórias do ecossistema em estudo. Estes relatos foram trazidos para a sala de aula, enriquecendo o entendimento sobre a relação da comunidade com a lagoa, de como ela se insere e se relaciona na vida social das pessoas que habitam seu entorno.

O diagnóstico ambiental foi feito em diferentes momentos, com alunos das turmas de Aceleração e $8^{\text {a }}$ série do currículo antigo do Ensino Fundamental e com turmas de $1^{\circ}, 2^{\circ}$ e $3^{\circ}$ anos do Ensino Médio. Com a turma de Aceleração, em 2003, o diagnóstico iniciou como atividade vinculada ao estudo dos seres vivos e da ecologia, envolvendo levantamento botânico e zoológico, com posterior identificação taxonômica por meio de chaves dicotômicas e sites científicos na internet, como também dos problemas socioambientais mais evidentes no ecossistema. Nos anos seguintes, os alunos do Ensino Fundamental e do Ensino Médio deram continuidade ao diagnóstico. $\mathrm{Na} 8^{\mathrm{a}}$ série as atividades de campo foram vinculadas ao estudo da água e dos ecossistemas aquáticos; no $1^{\circ}$ ano, ao estudo das propriedades dos seres vivos; no $2^{\circ}$ ano, ao conteúdo sobre biodiversidade e taxonomia; e no $3^{\circ}$, sobre a ecologia dos ecossistemas.

Nos anos 2012 e 2013, em parceria com pesquisadores da UNESC orientados pelo professor Dr. Carlyle Menezes, foi feito o monitoramento da qualidade da água da lagoa. Com o objetivo de buscar a participação da comunidade do entorno por meio da escola, os pesquisadores da Universidade ofereceram um ecokit com reagentes para as medições de características físicas da água (temperatura, turbidez e dureza) e químicas (Oxigênio, Ferro, Fosfato, Cloro, Amônia e pH). Também, capacitaram a pesquisadora para testá-los em campo junto com os alunos. Com o material científico e a experiência acadêmica propagada pelos pesquisadores, alunos da $8^{\mathrm{a}}$ série e alunos voluntários do Ensino Médio foram capacitados para fazer as coletas e realizar as medições com os reagentes. Os dados, anotados em formulários de Revbea, São Paulo, V. 11, № 4: 10-19, 2016. 
campo, foram digitalizados e transformados em gráficos para análise qualiquantitativa.

\section{Diagnóstico e monitoramento da Lagoa das Capivaras}

Sem a intenção de esgotar as investigações e discussões sobre o tema, os resultados foram organizados de modo a apresentarem e discutirem a identificação taxonômica das espécies de plantas e de cordados avistados, assim como as medições químicas e físicas da água por meio de gráficos. Também, proporcionam uma reflexão sobre a ecologia do ecossistema, o levantamento dos problemas socioambientais encontrados e sugestões propostas pelos alunos para a possível solução destes problemas.

\section{Fatores bióticos}

A identificação taxonômica foi feita a partir do avistamento dos animais in situ e da coleta de partes férteis das plantas, para posterior estudo bibliográfico com chaves dicotômicas e cadernos zoológicos e botânicos. Dada a dificuldade em distinguir certas variedades, algumas espécies foram identificadas até o nível taxonômico de gênero. Ao todo, foram levantadas 3 espécies de peixes de água doce, 3 espécies de répteis, 29 espécies de pássaros e 25 espécies botânicas, conforme as tabelas a seguir:

Conforme a Tabela 1, três espécies de peixes foram avistadas na lagoa: o cará, o jundiá e a traíra. Alguns alunos da classe de Aceleração tinham o hábito de pescar na lagoa como forma de recreação e contribuíram com seu conhecimento empírico na identificação dos peixes. Outro fato importante levantado foi o relato dos familiares pescadores de que a Lagoa das Capivaras, antes da urbanização do seu entorno, tinha uma barra que a ligava ao mar, permitindo a entrada de tainhas na época da piracema e constituindo-se numa significativa reserva de pesca para a comunidade. Atualmente, esta função de subsistência não é mais possível por causa da urbanização, que canalizou a barra e construiu casas e ruas sobre sua área original.

Tabela 1: Ictiofauna (peixes) da Lagoa das Capivaras.

\begin{tabular}{lcl}
\hline TAXA & NOME POPULAR & NOME CIENTÍFICO \\
\hline Characiforme & Traíra & Hoplias malabaricus \\
ERYTHRINIDAE & Cará & Geophagus brasiliensis \\
\hline $\begin{array}{l}\text { Perciforme } \\
\text { CICHLIDAE }\end{array}$ & Jundiá & Rhamdia sp. \\
\hline $\begin{array}{l}\text { Siluriforme } \\
\text { PIMELODIDEAE }\end{array}$ & PIME
\end{tabular}

Fonte: Autoria própria com o auxílio de chaves dicotômicas e cadernos de identificação, 2014.

Também foram avistadas três espécies de répteis na lagoa, como mostra a Tabela 2: o lagarto teiú, a cobra jararaca e o cágado tigre-d’água. Relatos dos familiares dos alunos da classe de Aceleração indicam que os 
cágados começaram a povoar a lagoa porque algumas pessoas abandonaram os animais no local. Antes da regularização da domesticação de animais silvestres pelo Instituto Brasileiro do Meio Ambiente e dos Recursos Naturais Renováveis (IBAMA), era comum a criação de cágados como animais de estimação, mas, à medida que cresciam e exigiam maiores cuidados, alguns cuidadores pensaram ser uma solução introduzi-los de volta à Natureza. Pelo que as observações in situ mostram, estes animais conseguiram adaptar-se ao ecossistema, tornando-se habitantes permanentes da lagoa. Os relatos também apontaram a incidência de jacarés-de-papo-amarelo há cerca de 50 anos. Após este período, não foram mais avistados.

Tabela 2: Fauna Reptiliana da Lagoa das Capivaras.

\begin{tabular}{lll}
\hline TAXA & NOME POPULAR & NOME CIENTÍFICO \\
\hline $\begin{array}{l}\text { SQUAMATA } \\
\text { Teiidae } \\
\text { Viperidae }\end{array}$ & $\begin{array}{l}\text { Lagarto Teiú } \\
\text { Cobra Jararaca }\end{array}$ & $\begin{array}{l}\text { Tupinambis merianae } \\
\text { Bothrops jararaca }\end{array}$ \\
\hline $\begin{array}{l}\text { TESTUDINATA } \\
\text { Emydidae }\end{array}$ & Cágado Tigre-d'água & Trachemys dorbigni \\
\hline $\begin{array}{l}\text { Fonte: Autoria própria com o auxílio de chaves dicotômicas e cadernos de identificação, 2014. } \\
\text { Fonto }\end{array}$
\end{tabular}

Segundo a Tabela 3, foram avistadas 29 espécies de pássaros distribuídas em 25 famílias e 13 ordens. Os passeriformes apresentaram maior riqueza de espécies, representadas em 10 famílias. Frango d'água, asa-deseda, andorinha-azul, corruíra, canário-da-terra, sabiá-branco e joão-de-barro foram as espécies observadas com maior frequência, enquanto 0 picapauzinho-barata, pardela-marrom e garibaldi foram avistados apenas uma vez. Os relatos da comunidade indicam que a marreca piadeira e o mergulhão eram frequentes na lagoa até 2002, porém a caça para alimentação acabou por dizimá-los deste ecossistema.

De acordo com a Tabela 4, foram identificadas 25 espécies representativas de plantas. As famílias com maior riqueza de espécies identificadas foram as leguminosas (com 4 espécies) e as mirtáceas (também com 4 espécies), todas exercendo importância ecológica por servirem de alimento e sítio de nidificação para os pássaros locais. Outras espécies encontradas também relevantes para a subsistência dos animais são a aroeiravermelha, o maracujazeiro, o gravatá e a embaúba. A espécie lantana é importante por atrair polinizadores como as borboletas e o araticum exerce papel fundamental na dinâmica e sobrevivência das espécies que habitam um pequeno mangue que se encontra na margem norte da lagoa. Suas raízes servem de berçário para o desenvolvimento de peixes e artrópodos, considerados de extrema importância para a dinâmica da teia alimentar no ecossistema. A carqueja, a cavalinha e a erva-baleeira são usadas como plantas medicinais pela comunidade local e crescem espontaneamente no entorno da lagoa. A macrófita aquática salvínia tem o papel de contribuir para a reposição de nitrogênio no ecossistema e serve de habitat para protistas e 
artrópodos. No entanto, dada a alta deposição de matéria orgânica no corpo d'água da lagoa, seu crescimento exagerado cobre a superfície, impedindo a entrada de luz solar e aumentando a deposição de matéria orgânica em decomposição no fundo da lagoa, contribuindo também para o processo de eutrofização.

Tabela 3: Ornitofauna (aves) da Lagoa das Capivaras.

\begin{tabular}{|c|c|c|}
\hline TAXA & NOME POPULAR & NOME CIENTÍFICO \\
\hline $\begin{array}{l}\text { ACCIPITRIFORMES } \\
\text { Accipitridae }\end{array}$ & Gavião-carijó & Buteo magnirostris \\
\hline $\begin{array}{l}\text { ANSERIFORMES } \\
\text { Anatidae }\end{array}$ & Marreca-piadeira, Irerê & Dendrocygna viduata \\
\hline $\begin{array}{l}\text { CATHARTIFORMES } \\
\text { Cathartidae }\end{array}$ & Urubu & Coragyps atratus \\
\hline $\begin{array}{l}\text { CICONIIFORMES } \\
\text { Ardeidae } \\
\text { Threskiornithidae }\end{array}$ & $\begin{array}{l}\text { Garça-branca-pequena } \\
\text { Maçarico-preto }\end{array}$ & $\begin{array}{l}\text { Egretta thula } \\
\text { Phimosus infuscatus }\end{array}$ \\
\hline $\begin{array}{l}\text { CHARADRIIFORMES } \\
\text { Charadriidae } \\
\text { Jacanidae } \\
\text { Laridae }\end{array}$ & $\begin{array}{l}\text { Quero-quero } \\
\text { Asa-de-seda, Jaçanã } \\
\text { Gaivota }\end{array}$ & $\begin{array}{l}\text { Vanellus chilensis } \\
\text { Jacana jacana } \\
\text { Larus dominicanus }\end{array}$ \\
\hline $\begin{array}{l}\text { COLUMBIFORMES } \\
\text { Columbidae }\end{array}$ & Rolinha & Columbina talpacoti \\
\hline $\begin{array}{l}\text { CUCULIFORMES } \\
\text { Cuculidae }\end{array}$ & $\begin{array}{l}\text { Anu-preto } \\
\text { Anu-branco }\end{array}$ & $\begin{array}{l}\text { Crotophaga ani } \\
\text { Guira guira }\end{array}$ \\
\hline $\begin{array}{l}\text { GRUIFORMES } \\
\text { Ralidae }\end{array}$ & Frango-d'água & Gallinula chloropus \\
\hline $\begin{array}{l}\text { PASSERIFORMES } \\
\text { Emberizidae }\end{array}$ & $\begin{array}{l}\text { Canário-da-terra } \\
\text { Sanhaçu }\end{array}$ & $\begin{array}{l}\text { Sicalis flaveola } \\
\text { Thraupis sayaca }\end{array}$ \\
\hline $\begin{array}{l}\text { Furnariidae } \\
\text { Hirundinidae } \\
\text { Icterida } \\
\text { Mimidae } \\
\text { Muscicapidae } \\
\text { Parulidae } \\
\text { Ploceidae } \\
\text { Troglodytidae } \\
\text { Tyrannidae }\end{array}$ & $\begin{array}{l}\text { João-de-barro } \\
\text { Andorinha-azul } \\
\text { Garibaldi } \\
\text { Sabiá-do-campo } \\
\text { Sabiá-branco } \\
\text { Cambacica } \\
\text { Pardal } \\
\text { Corruíra } \\
\text { Bem-te-vi } \\
\text { Siriri }\end{array}$ & $\begin{array}{l}\text { Furnarius rufus } \\
\text { Notiochelidon cyanoleuca } \\
\text { Agelaius ruficapillus } \\
\text { Mimus saturninus } \\
\text { Turdus leucomelas } \\
\text { Coereba flaveola } \\
\text { Passer domesticus } \\
\text { Troglodytes aedon } \\
\text { Pitangus sulphuratus } \\
\text { Tyrannus melancholicus }\end{array}$ \\
\hline $\begin{array}{l}\text { PELECANIFORMES } \\
\text { Fregatidae }\end{array}$ & Fragata & Fregata magnificens \\
\hline $\begin{array}{l}\text { PICIFORMES } \\
\text { Picidae }\end{array}$ & Pica-pauzinho-barata & Picumnus cirratus \\
\hline $\begin{array}{l}\text { PODICIPEDIFORMES } \\
\text { Podicipedidae }\end{array}$ & Mergulhão & Podilymbus podiceps \\
\hline $\begin{array}{l}\text { TROCHILIFORMES } \\
\text { Trochilidae }\end{array}$ & $\begin{array}{l}\text { Beija-flor-de-garganta-verde } \\
\text { Beija-flor-de-papo-branco }\end{array}$ & $\begin{array}{l}\text { Amazilia fimbriata } \\
\text { Leucochloris albicollis }\end{array}$ \\
\hline
\end{tabular}


Tabela 4: Flora representativa da Lagoa das Capivaras.

\begin{tabular}{|c|c|c|}
\hline TAXA & NOME POPULAR & NOME CIENTÍFICO \\
\hline \multicolumn{3}{|l|}{ PTERYDOPHYTA } \\
\hline Blechnaceae & Blechnum & Blechnum sp. \\
\hline Equisetaceae & Cavalinha & Equisetum giganteum \\
\hline Lycopodiaceae & Licopódio & Licopodium sp. \\
\hline Salviniaceae & Salvínia & Salvinia sp. \\
\hline \multicolumn{3}{|l|}{ MAGNOLIOPHYTA } \\
\hline Anacardiaceae & Aroeira-vermelha & Schinnus therebinthifolia \\
\hline Annonaceae & Araticum & Annona rugulosa \\
\hline Asteraceae & Carqueja & Baccharis genistelloides \\
\hline Boraginaceae & Erva-baleeira & Cordia verbenácea \\
\hline Bromeliaceae & Gravatá & Vriesia sp. \\
\hline Cyperaceae & Tiririca & Cyperus sp. \\
\hline Droseraceae & Orvalhinha & Drosera brevifolia \\
\hline \multirow[t]{4}{*}{ Leguminosae } & Ingá & Inga uruguensis \\
\hline & Maricá & Mimosa bimucronata \\
\hline & Pega-pega & Desmodium adscendens \\
\hline & Sensitiva & Mimosa pudica \\
\hline Melastomataceae & Quaresmeira-roxa & Tibouchina granulosa \\
\hline \multirow[t]{4}{*}{ Myrtaceae } & Eucalipto & Eucaliptus sp. \\
\hline & Goiabeira & Psidium guayava \\
\hline & Jambolão & Syzygium cumini \\
\hline & Pitangueira & Eugenia uniflora \\
\hline Passifloraceae & Maracujazeiro & Passiflora edulis \\
\hline Urticaceae & Embaúba & Cecropia glaziovii \\
\hline Verbenaceae & Lantana & Lantana camara \\
\hline \multicolumn{3}{|l|}{ PINOPHYTA } \\
\hline Casuarinaceae & Casuarina & Casuarina $s p$ \\
\hline Pinaceae & Pinheiro & Pinus sp. \\
\hline
\end{tabular}

Fonte: Autoria própria com o auxílio de chaves dicotômicas e cadernos de identificação, 2014.

A AMA, em colaboração com moradores da cidade, promoveu mutirões de limpeza da lagoa, removendo o excesso de salvínias para produzir adubo orgânico e retirando o lixo. A AMA também fez mutirões para plantio de árvores nativas para repovoar o ecossistema do entorno da lagoa, mas funcionários da prefeitura e moradores roçaram parte do território alegando estarem "limpando 
o mato". Alguns moradores da cidade costumam amarrar gado para pastar no local, resultando no pisoteamento e consumo das plantas por estes animais. Um achado curioso foi a presença de dróseras (plantas carnívoras) somente sobre montes de areia branca litorânea. Moradores locais comentaram ser este material proveniente de restos de obras no entorno do ecossistema. A drósera é uma espécie típica de dunas e sua ocorrência na beira da lagoa pode ter tido origem nas sementes carregadas junto da areia extraída para construção civil e depois descartada como entulho na beira do corpo d'água. Além das espécies nativas da região, há incidência de plantas exóticas provenientes das podas dos jardins das casas próximas. Também, entre as exóticas, destacam-se as árvores invasoras casuarina, pinus e eucalipto, que se proliferam espontaneamente pelos diferentes ecossistemas do município. Segundo os relatos dos familiares dos alunos, estas espécies foram trazidas pelos colonizadores europeus para a construção de casas e a produção de lenha. Ainda, foi observada a alta incidência de líquens de diferentes tipos nos troncos das árvores, indicando que a qualidade do ar no ecossistema mantém-se boa, pois estes seres simbiontes são muito sensíveis à poluição atmosférica.

\section{Impactos socioambientais observados pelos alunos}

- Desmatamento contínuo da vegetação do entorno;

- aterros urbanos que reduziram o diâmetro original da lagoa a menos de um terço do seu tamanho original;

- invasão imobiliária na Área de Preservação Permanente que obstrui o acesso à lagoa, além de reduzir a sua área silvestre;

- saída de efluentes canalizados para a lagoa;

- acúmulo de entulhos de obras adjacentes;

- presença de lixo e detritos humanos na água e no entorno da lagoa;

- presença de entulhos e lixos na área de mangue, obstruindo locais de potencial nidificação de espécies da base da teia alimentar;

- extração de lenha da área próxima ao mangue, alterando a paisagem, interferindo na nidificação dos pássaros e reduzindo a área de amortecimento entre a lagoa e o ambiente urbano;

- presença de armadilhas para a caça de aves silvestres, prática que reduz a riqueza de espécies, diminui a dispersão de sementes, também eliminando presas e predadores fundamentais para a teia alimentar;

- desaparecimento de espécies nativas da região, como a marrecapiadeira, o mergulhão, o jacaré-de-papo amarelo e a própria capivara que deu nome à lagoa, consoante relato dos antigos moradores;

- introdução de espécies exóticas que alteraram a paisagem e a dinâmica do ecossistema, como o eucalipto (que absorve grandes quantidades de água no verão, podendo comprometer o abastecimento das espécies no 
seu entorno), o pinus e a casuarina, cujas folhas em forma de agulha são de difícil decomposição e que contêm substâncias que repelem o crescimento de outras espécies locais; e a salvínia, que, após ser introduzida na lagoa, proliferou-se de modo a cobrir a superfície, impedindo a incidência de luz dentro do corpo d'água;

- presença de vestígios de acampamentos irregulares numa pequena área ao norte da lagoa, como restos de fogueira, dejetos fecais destinados inadequadamente e lixo de embalagens de alimentos;

- vestígios de uso frequente de drogas lícitas e ilícitas, também na borda norte, como restos de seringa, garrafas de bebidas alcoólicas, bitucas de cigarro, papelotes e latas furadas de alumínio.

\section{Soluções propostas pelos alunos}

- Capacitação e remuneração de agentes comunitários para limpeza, manutenção e fiscalização da área da Lagoa das Capivaras;

- criação de um viveiro de mudas de espécies nativas para o repovoamento e remanejo dos ecossistemas locais e regionais degradados, possibilitando a venda para fins de manutenção do viveiro;

- criação de uma trilha ecológica de baixo impacto para visitações educativas planejadas sob orientação de um profissional habilitado;

- exigir do poder público o cumprimento das leis ambientais, de modo a conter as obras de potencial impacto ambiental e incentivar aquelas que se pautem na sustentabilidade do meio ambiente e da sociedade;

- estabelecer parcerias entre a comunidade, o poder público e as empresas privadas no desenvolvimento e investimento em projetos de conservação, manejo ambiental e sustentabilidade socioambiental;

- envolver a comunidade por meio das escolas e das diferentes associações comunitárias de modo a participarem como protagonistas no processo de gestão.

O diagnóstico preliminar realizado pela classe de Aceleração e suas sugestões foram apresentados e discutidos com a comunidade na Mostra José Lutzemberger de 2003, evento que é realizado todos os anos pelo Projeto Gaia Village em Garopaba, com a participação das escolas municipais, estaduais e privadas da região, além de diferentes atores sociais na causa ambiental.

\section{Monitoramento da água}

O aspecto da água na Lagoa das Capivaras é turvo nas margens, não sendo possível enxergar o seu fundo a partir da superfície. A profundidade da lagoa foi medida com um galho em 2003 e indicou 1,5 m. Foram encontradas diversas saídas de efluentes, além de alguns focos de poluição química (em alguns lugares, havia uma coloração rosa metálica próxima à borda leste, além 
de um odor desagradável). Muitos sacos plásticos, garrafas de vidro e embalagens de alimento - como salgadinhos, balas e bolachas recheadas foram encontrados na superfície da água e entorno da lagoa, provenientes de visitantes e da destinação inadequada de lixo urbano arrastado pelo vento. Constatou-se a ocorrência de matéria orgânica em decomposição no fundo do corpo d'água. Os resultados das análises químicas e físicas consta nas Figuras a seguir.

Conforme a Figura 1, as análises físicas da água realizadas em 2012 indicam taxas normais de temperatura, turbidez e dureza, com uma pequena variação nestes dois últimos após um breve período de chuvas no mês de agosto, o que causou a diluição da água.
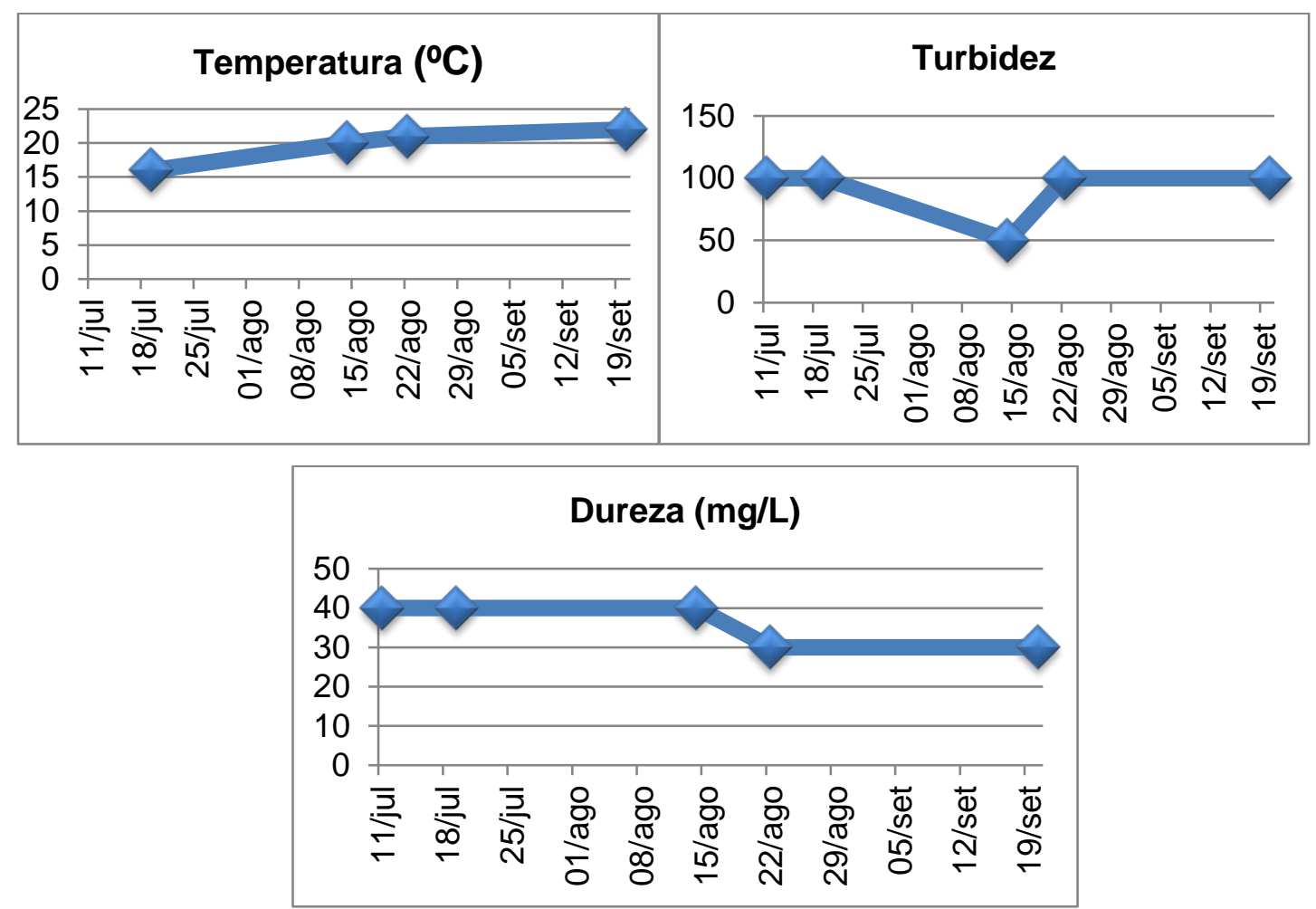

Figura 1: Gráficos das análises físicas da água.

Fonte: Autoria própria, 2012.

As análises químicas expostas na Figura 2 mostram quantificações normais de oxigênio (segundo o padrão da Resolução do Conselho Nacional do Meio Ambiente (CONAMA) no 357/05 (BRASIL, 2005) não deve ser inferior a $5 \mathrm{mg} / \mathrm{l}$ ), Ferro (que no padrão CONAMA não deve ultrapassar $0,3 \mathrm{mg} / \mathrm{l}$ ) e ortofosfato (que deve ser ausente). A taxa de cloreto mostrou-se bastante elevada. O nível médio de cloreto da água mineral para consumo humano é de $2 \mathrm{mg} / \mathrm{l}$, mas os valores encontrados extrapolaram para até $40 \mathrm{mg} / \mathrm{l}$. É possível que este resultado seja proveniente da poluição por produtos químicos domésticos que levam cloro em sua composição. A taxa de amônia também apresentou-se elevada, ultrapassando o $0,4 \mathrm{mg} / \mathrm{l}$ do limite padrão sugerido pelo

Revbea, São Paulo, V. 11, № 4: 10-19, 2016. 
CONAMA. A amônia também é uma substância química comum em produtos de uso doméstico, em especial, relacionados à limpeza de casas. $\mathrm{O} \mathrm{pH}$ da água manteve-se num valor próximo ao neutro.
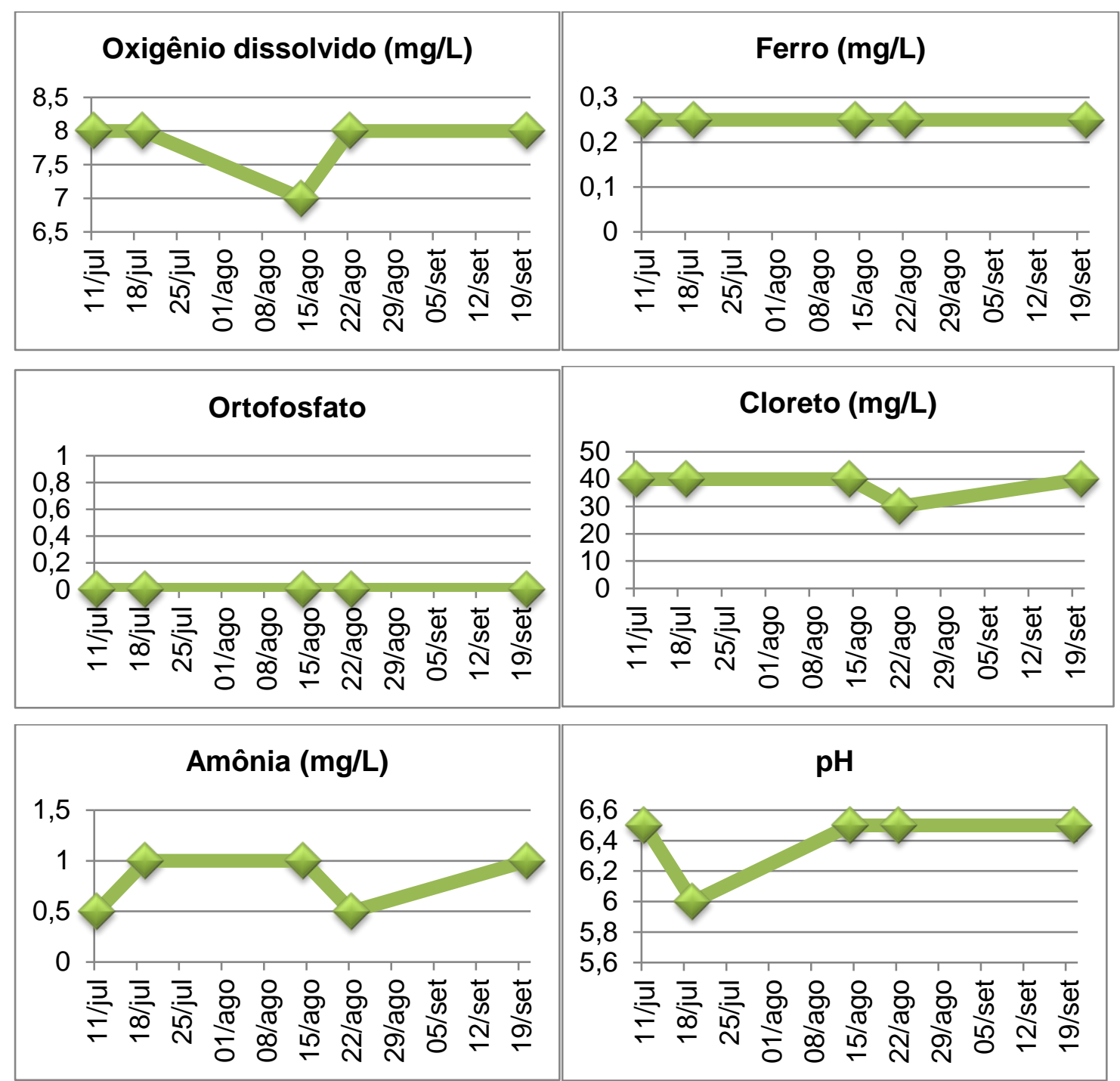

Figura 2: Gráficos das análises químicas da água.

Fonte: Autoria própria, 2012.

revista brasileira educação ambiental

Estes resultados demonstram que, apesar de algumas alterações significativas nas quantidades de cloro e amônia, a água da Lagoa das Capivaras ainda apresentou características físicas e químicas com qualidade suficiente para manter o desenvolvimento de uma diversidade considerável de espécies neste ecossistema. A preservação da lagoa e seu entorno é imprescindível para a continuidade da qualidade deste ambiente, que é fundamental não apenas para as espécies botânicas e de animais, mas também para a sociedade que vive em Garopaba e região. Também, urge a necessidade de se desenvolver ações no sentido de conter a poluição química

Revbea, São Paulo, V. 11, № 4: 10-19, 2016. 
de cloreto e amônia, por meio de intervenções na comunidade e entorno, investigação e mitigação da origem de escoamento e o contínuo monitoramento da qualidade da água para controle e manejo do ecossistema.

De acordo com a Figura 3, as análises físicas da água em 2013 indicaram valores normais de temperatura (com sensível aumento conforme as estações tornavam-se mais quentes), turbidez e dureza.
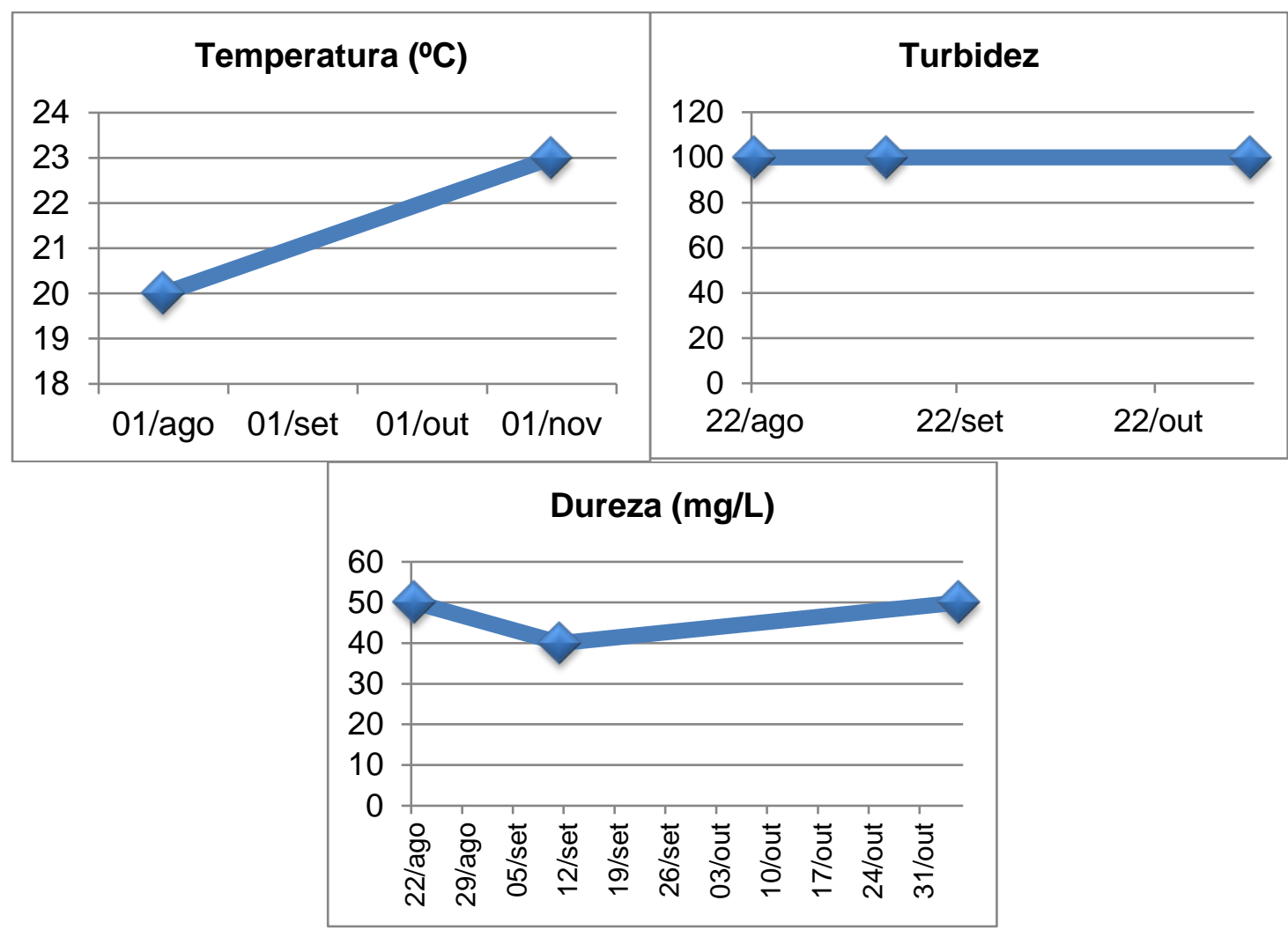

Figura 3: Gráficos das análises físicas da água.

Fonte: Autoria própria, 2013.

As análises químicas ilustradas na Figura 4 mostraram taxas normais de oxigênio e $\mathrm{pH}$. Mas também indicaram valores altos de cloreto e amônia, repetindo o padrão encontrado em 2012. Ferro e ortofosfato revelaram resultados normais, com exceção da medição do dia 12 de setembro, quando se mediu a presença de $0,5 \mathrm{mg} / \mathrm{l}$ de ortofosfato e também de ferro, estando sensivelmente acima do padrão CONAMA. A hipótese levantada foi a possibilidade de algum evento pontual ter descarregado poluentes desta natureza no corpo d'água da Lagoa das Capivaras, pois estes valores não foram encontrados na medição seguinte. Estas análises também indicaram uma qualidade da água relativamente propícia para o desenvolvimento da vida aquática e do entorno da lagoa, apesar de alguns valores estarem acima do padrão CONAMA. 

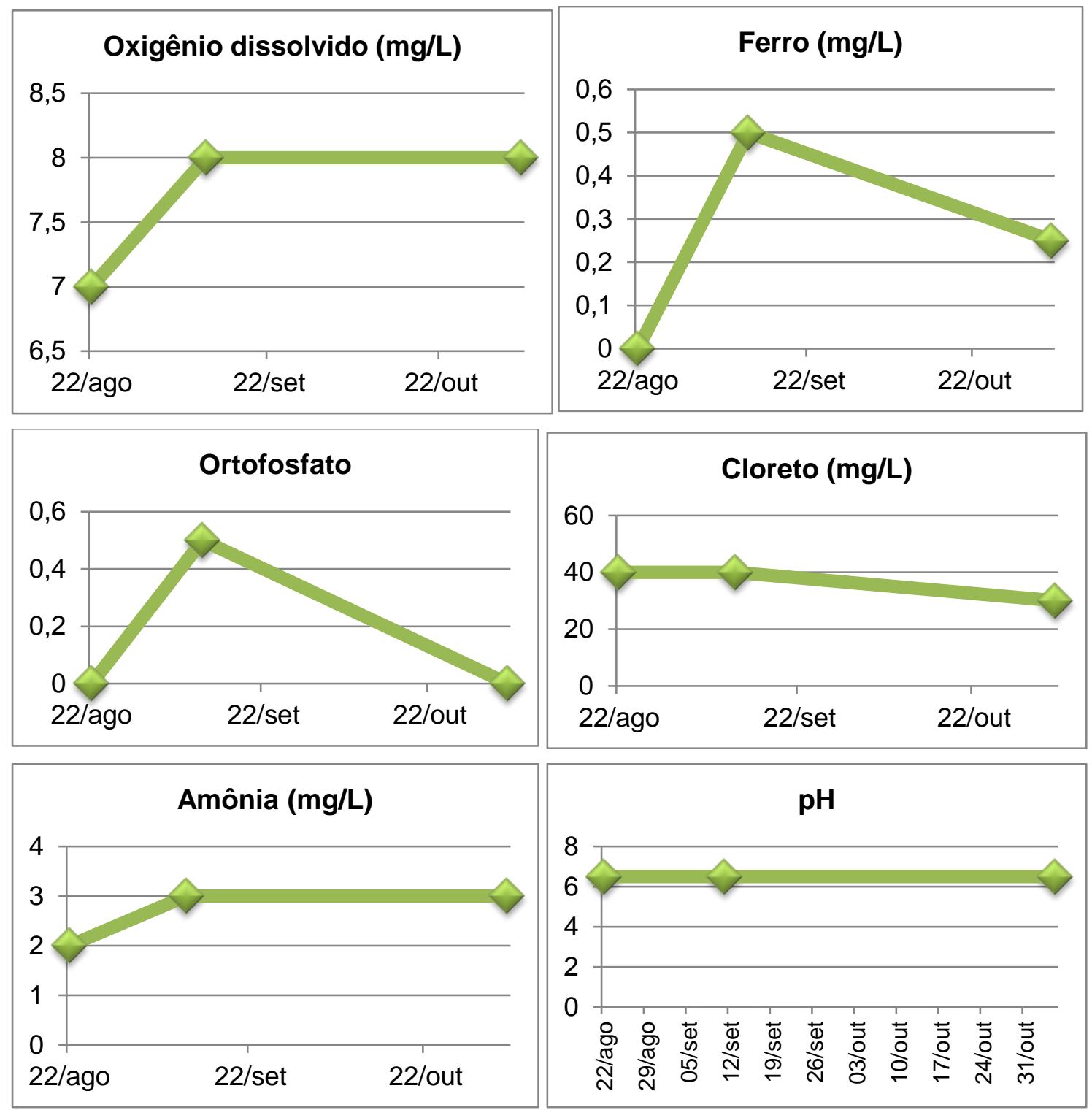

Figura 4: Gráficos das análises químicas da água.

Fonte: Autoria própria, 2013.

Como as medições foram realizadas apenas no segundo semestre de cada ano - depois de seis meses após o boom populacional de verão sugeriu-se que novas análises também sejam feitas no primeiro semestre após o período de férias. Neste caso específico, há um grande crescimento populacional e uma maior concentração de detritos na cidade, o que torna possível fazer uma comparação e um diagnóstico mais acurado da qualidade da água da lagoa considerando sua dinâmica socioambiental em relação ao ciclo sazonal. Os valores preliminares das análises também foram apresentados e discutidos com a comunidade na Feira Regional de Ciências e Tecnologia de Laguna, realizada em 2013. Neste evento, alunos voluntários do projeto puderam interagir com alunos e professores de outras escolas estaduais da Regional de Laguna, assim como representantes do poder público 
estadual ligados à educação. Os resultados destes dez anos de EA na Lagoa das Capivaras foram apresentados em palestras no III Encontro Sul Brasileiro de Educação Patrimonial, como também na Semana Acadêmica da Biologia, ambos os eventos realizados na UNISUL, em Tubarão, no ano de 2014. Em 2015, este trabalho também foi destacado - junto de outras práticas ecopedagógicas - como um trabalho diferenciado em ciências e motivador para os alunos, em comunicação oral no VII Simpósio sobre Formação de Professores, também na UNISUL. A participação da pesquisadora nestes eventos como palestrante foi uma forma de valorizar o trabalho expandindo a discussão do tema para a realidade acadêmica.

\section{Considerações sobre a experiência}

Este trabalho mostrou claramente o potencial da EA não apenas na construção do conhecimento, como também na sua produção por meio da metodologia científica de investigação de campo, utilizando-se das ferramentas de diagnóstico e monitoramento. As aulas diferenciadas propostas foram atrativas e motivadoras para a aprendizagem, como também para 0 engajamento dos jovens nas questões socioambientais da comunidade.

De modo a dialogar com o saber científico sistematizado, houve a valorização do saber do aluno e da comunidade, o que contribuiu para um entendimento mais holístico das relações socioambientais no ecossistema em estudo. Demonstrou que a lagoa foi importante para a subsistência dos moradores locais nos períodos em que não era possível pescar no mar; também, como a caça sem critérios fez desaparecer espécies frequentes. Ainda, contribuiu significativamente para a identificação científica das espécies encontradas, uma vez que os alunos que tinham experiências empíricas concretas no ambiente da lagoa estavam familiarizados com o ecossistema e possuíam conhecimentos de vivências cotidianas que colaboraram consideravelmente para um entendimento mais amplo do ambiente. Neste sentido, alguns alunos que eram estigmatizados na escola por suas dificuldades de aprendizagem encontraram espaço para partilhar seus conhecimentos empíricos de vivência neste ecossistema, contribuindo para a construção e produção de conhecimentos e para a melhoria da autoestima por meio da valorização das experiências de vida. Também, os alunos participantes, no geral, relataram interessarem-se mais pelos conhecimentos e métodos científicos de pesquisa, sentindo-se mais confiantes e motivados a buscarem na Universidade a continuidade dos seus estudos após se formarem na Educação Básica.

Apesar das limitações estruturais de uma escola pública, o engajamento dos participantes e a parceria com a Universidade mostram-se prolíficos e importantes no desenvolvimento da pesquisa pelos educandos, seja capacitando-os para a investigação científica de monitoramento, seja abrindo um canal de relacionamento educativo recíproco entre a comunidade - através da escola - e a Universidade - por meio dos pesquisadores acadêmicos e 
instrumentos de análise. Esta experiência constituiu-se num exemplo concreto de que a parceria entre a escola pública e a Universidade gera resultados positivos na construção e produção de conhecimento científico pertinente à discussão sobre a conservação dos ecossistemas e a sustentabilidade socioambiental.

Outro fato relevante a ressaltar sobre o trabalho é que os resultados do diagnóstico e do monitoramento indicam que, mesmo em vias de degradação, a Lagoa das Capivaras ainda abriga uma grande diversidade de espécies, constituindo-se num espaço de desenvolvimento da vida. Por este motivo, é urgente a mobilização para a criação de políticas públicas para sua conservação e manejo sustentável, considerando sua importância para a comunidade no passado, no presente e suas potencialidades para o futuro.

\section{Agradecimentos}

À UNISUL, pela oportunidade de aprofundar meus estudos em Educação e produzir materiais de minhas experiências sobre o tema; à UNESC, pela parceria entre Universidade e Escola que permitiu aos jovens fazer Ciência na Educação Básica; e à Escola de Educação Básica Professor José Rodrigues Lopes, cujos alunos foram os verdadeiros protagonistas desta história.

\section{Referências}

ANASTASIOU, L.G.C.; ALVES, L.P. Estratégias de Ensinagem. Processos de Ensinagem na Universidade. Joinville: Univille, 2003.

ASSEMBLEIA LEGISLATIVA ESTADO DO RIO GRANDE DO SUL. Relatório da Comissão Especial das Águas. Porto Alegre: ALRS, 2004.

BRAGA, R.N.; MARCOMIN, F.E. Percepção ambiental como ferramenta para educação ambiental: uma investigação junto a moradores e veranistas do entorno da Lagoa do Arroio Corrente - Jaguaruna - Santa Catarina. In: MENDONÇA, A.W; SIQUEIRA A.B.; MARCOMIN, F.E. (Org.). Educação, Sociedade e Meio Ambiente no Estado de Santa Catarina: múltiplas abordagens. São Leopoldo: Oikos, 2012. p:157-183.

BRASIL. Coletânea de Legislação de Direito Ambiental. São Paulo: Revista dos Tribumais, 2002.

BRASIL. Senado Federal. Decreto de 14 de setembro de 2000. Dispõe sobre a Área de Proteção Ambiental da Baleia Franca. Disponível em: $<$ http://www.senado.gov.br/legislacao $>$. Acesso em: 02 set. 2014.

BRASIL. Ministério do Meio Ambiente. Resolução no 357, de 17 de março de 2005. Dispõe sobre a classificação dos corpos de água e estabelece condições e padrões de lançamento de efluentes. Disponível em: <http://www.mma.gov.br/port/conama/res/res05/res35705.pdf>. Acesso em: 18. nov. 2015.

Revbea, São Paulo, V. 11, № 4: 10-19, 2016. 
CAPRA, F. As Conexões Ocultas: ciência para uma vida sustentável. São Paulo: Cultrix, 2003.

CARVALHO, I.C.M. A Invenção do Sujeito Ecológico: identidade e subjetividade na formação dos educadores ambientais. In: SATO, M.; CARVALHO, I.C.M. (Org.). Educação Ambiental. Porto Alegre: Artmed, 2005. p: 53-65.

COSTA, P.D.; MENEZES, C.T.B. Instrumentos de Capacitação Comunitária Aplicados no Litoral Centro-sul de Santa Catarina. Artigo enviado para publicação nos anais do VII Simpósio Brasileiro de Engenharia Ambiental - VII SBEA. 29 e 30 de Abril a 01 de Maio de 2012 - Criciúma, SC, baseado em dados de Trabalho de Conclusão de Graduação em Engenharia Ambiental pela Universidade do Extremo-sul Catarinense. Criciúma, 2012.

DIAS, G.F. Educação Ambiental: princípios e práticas. São Paulo: Gaia, 2000.

FREIRE, P. Pedagogia da Autonomia: saberes necessários à prática educativa. 15. ed. São Paulo: Paz e Terra, 2000.

LAYRARGUES, P.P. (coord.). Identidades da Educação Ambiental Brasileira. Brasília: Ministério do Meio Ambiente, 2004.

MARIANO, N.M.; MENEZES, C.T.B. Diagnóstico Ambiental como Subsídio para Recuperação de Lagoas Costeiras: estudo de caso da Lagoa das Capivaras - Garopaba - SC. 2010. Dissertação (Mestrado em Ciências Ambientais)-Universidade do Extremo Sul Catarinense, Criciúma, 2010.

MORELLI, L. Grito das Águas. Joinville: Letradágua, 2001.

OLIVEIRA, C. M. Educação Ambiental com Classes de Aceleração: o trabalho mediador da escola na gestão ambiental da Lagoa das Capivaras e na formação cidadã. 2004. Monografia (Especialização em Gestão Ambiental: Educação e Sociedade)-Instituto Superior de Educação e PósGraduação/Associação Catarinense de Ensino, Florianópolis, 2004.

PITSCH, R. et al. Lógica da Ciência: iniciação por exercício. 14. ed. São Leopoldo: UNISINOS, 1998.

RIO GRANDE DO SUL. Assembleia Legislativa. Relatório da Comissão Especial das Águas. Porto Alegre: ALRS, 2004. 